\title{
Asymmetric catalytic arylation of ethyl glyoxylate using organoboron reagents and $\mathrm{Rh}(\mathrm{l})$-phosphane and phosphane-phosphite catalysts $\uparrow$
}

\author{
Carolina Silva Marques, ${ }^{a}$ Mehmet Dindaroğlu, ${ }^{\mathrm{b}}$ Hans-Günther Schmalz ${ }^{\mathrm{b}}$ \\ and Anthony J. Burke*a
}

Herein we report the first application of $\mathrm{Rh}(1)$-phosphane and phosphane-phosphite catalysts in the enantioselective catalytic arylation of ethyl glyoxylate with organoboron reagents, providing access to ethyl mandelate derivatives in high yield (up to 99\%) and moderate to very good enantioselectivities (up to $75 \%$ ee). Commercial phosphane ligands, such as $(R)$-MonoPhos and $(R)$-Phanephos were tested, as well as non-commercial $(R, R)$-TADDOL-derived phosphane-phosphite ligands. Those ligands containing bulky substituents in the ortho-and para-positions of the chiral phosphite moiety were found to be the most selective.

Received 25th November 2013 Accepted 16th December 2013

DOI: $10.1039 / \mathrm{c} 3 \mathrm{ra} 47000 \mathrm{~h}$

www.rsc.org/advances

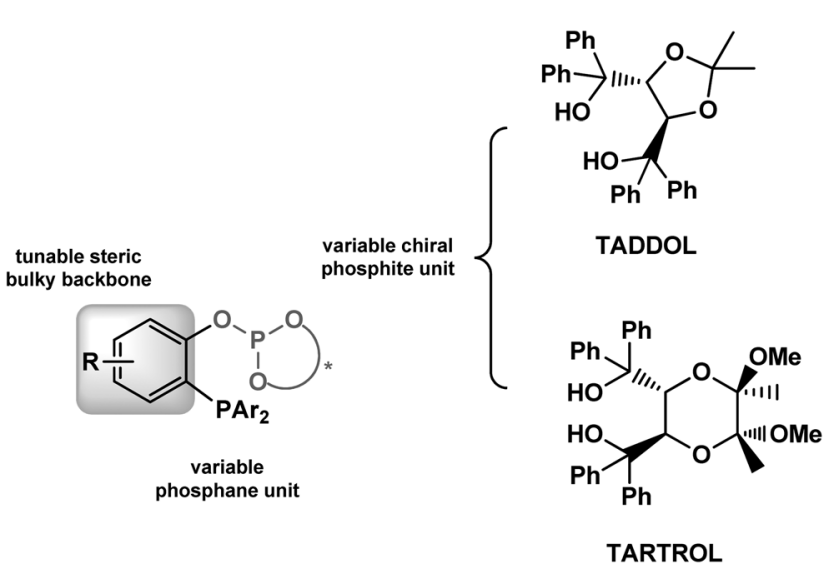

Fig. 1 General structure of the modular phosphane-phosphite ligands introduced by Schmalz's group. ${ }^{10}$

have recently developed a class of modular chiral phosphanephosphite ligands (Schmalz ligands), prepared from TADDOL ${ }^{8}$ and TARTROL ${ }^{9}$ building blocks (Fig. 1), and which have been used in several transition metal-catalysed reactions. ${ }^{10}$ We decided to test these ligands for the first time, in the transition metal-catalysed arylation of ethyl glyoxylate, using organoboron reagents and $\mathrm{Rh}(\mathrm{I})$ pre-catalysts.

\section{Results and discussion}

Miyaura and co-workers already reported a non-asymmetric rhodium-catalysed addition of organoboronic acids to aldehydes using several racemic phosphane ligands. ${ }^{11 a, b}$ With regard to the synthesis of mandelate derivatives, Francesco and coworkers reported a non-asymmetric Suzuki-Miyaura coupling 
reaction of organoboronic acids and ethyl glyoxylate using $\operatorname{Pd}(0)$ catalysts. ${ }^{12}$ In 2012, Yamamoto and co-workers reported the addition of arylboronic acids to ethyl glyoxylate catalysed by a $\mathrm{Ru} / \mathrm{Me}-\mathrm{BIPAM}$ complex, giving mandelate derivatives in high yields and enantioselectivities. ${ }^{13}$

Based on our previous work on the synthesis of ethyl mandelate derivatives using $\mathrm{Rh}(\mathrm{I})-\mathrm{NHC}$ catalysts, ${ }^{1 d, e}$ and our unsuccessful attempts at obtaining high enantioselectivities, we initiated a focused program at screening various chiral phosphorous ligands in an attempt at increasing the enantioselectivities. The study was based on the same methodology previously employed ${ }^{1 d, e}$ and besides the commercial bidentate phosphane ligands (Fig. 2): (R)-Phanephos (1), commonly used for asymmetric hydrogenations, ${ }^{14}(R, R)$-Chiraphos (2), $(R)$ MonoPhos (3) and other phosphoramidite type derivatives (4) and (5) were also employed. The results can be seen in Table 1. In the case of $(R)$-Phanephos (1) (Fig. 2), full conversion into ethyl mandelate was observed (Table 1, entry 1) but with poor enantiocontrol $\left(<5 \%\right.$ ee). $\mathrm{Rh}(\mathrm{acac})\left(\mathrm{C}_{2} \mathrm{H}_{4}\right)_{2}$ is a pre-catalyst, which was already applied with success by Hayashi's group in the rhodium-catalyzed asymmetric 1,4-addition of aryl- and alkenylboronic acids to enones. ${ }^{15 a}$ When we used this precatalyst, only a moderate yield and a poor enantioselectivity was obtained (Table 1, entry 2). By testing the same reaction conditions at room temperature in an attempt to improve the enantioselectivity, a good enantioselectivity of $75 \%$ ee was obtained, unfortunately with a low yield (see Table 1, entry 3 ). We decided to test the less bulkier commercial $(R, R)$-Chiraphos (2) ligand (Fig. 2) using the same reaction conditions, since it was successfully applied by Miyaura's group for the conjugate addition of organoboron, organosilicon, and organobismuth reagents to $\alpha, \beta$-unsaturated ketones. ${ }^{11 c}$ The reaction was nonenantioselective, and the racemic ethyl mandelate product was obtained, with moderate yield ( $48 \%$ yield) (see Table 1, entry 4 ).

Inspired by the work developed by Yamamoto and coworkers, ${ }^{13}$ we decided to use the chiral commercial phosphoramidite ligand (R)-MonoPhos (3) (Fig. 2) under these reaction conditions. These ligands reported by Feringa's group were shown to be privileged in several asymmetric catalytic reactions. ${ }^{16}$ Excellent yields were obtained with this ligand, using several $\mathrm{Rh}(\mathrm{I})$ pre-catalysts (see Table 1 , entries 5 to 8 ), but only

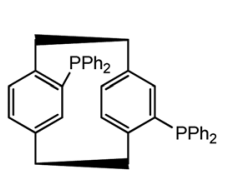

(R)-(-)-Phanephos (1)

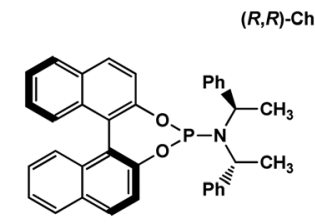

(4)

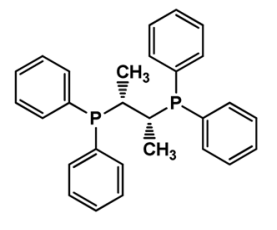

$R, R)$-Chiraphos (2)

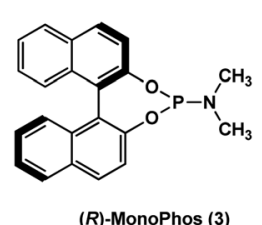

(R)-MonoPhos (3)

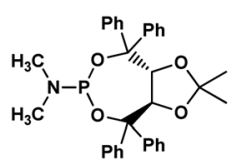

(5)
Fig. 2 Commercial phosphorous containing ligands.
Table $1 \mathrm{Rh}(\mathrm{I})$ catalysed enantioselective arylation of ethyl glyoxylate with phenylboronic acid

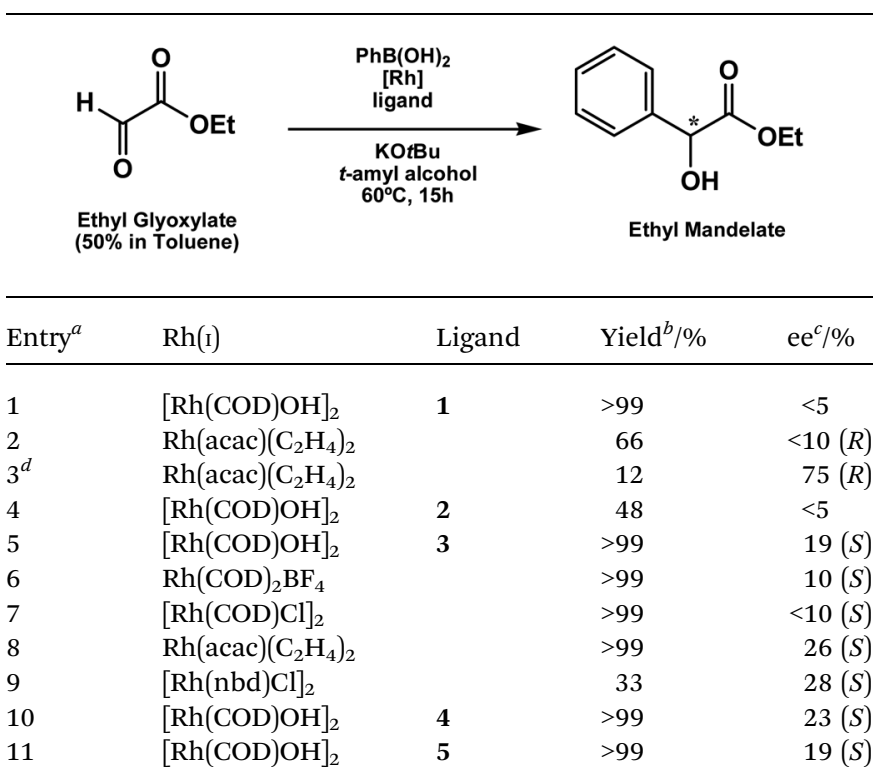

${ }^{a}$ Reaction conditions: $1.5 \mathrm{~mol} \%[\mathrm{Rh}(\mathrm{I})]_{2}$ or $3 \mathrm{~mol} \%[\mathrm{Rh}(\mathrm{I})], 3.3 \mathrm{~mol} \%$ Ligand, 2 equivalents $\mathrm{PhB}(\mathrm{OH})_{2}, 2$ equivalents $\mathrm{KO} t \mathrm{Bu}, 1 \mathrm{ml} t$-amyl alcohol, $100 \mu \mathrm{l}$ ethyl glyoxylate. ${ }^{b}$ Isolated yield after silica gel chromatography. ${ }^{c}$ Determined by chiral stationary phase HPLC. ${ }^{d}$ Reaction run at room temperature.

low enantioselectivities were observed. Since this reaction appeared to be highly dependent on the rhodium complex, the bulky $\mathrm{Rh}(\mathrm{I})$ pre-catalyst $[\mathrm{Rh}(\mathrm{nbd}) \mathrm{Cl}]_{2}$ was tested with this ligand (Table 1 , entry 9), but only a $33 \%$ yield was obtained and an enantioselectivity of only $28 \%$ ee with $(R)$-MonoPhos (3). In a final attempt to improve the enantioselectivity, we decided to test the commercial chiral Monophos derivatives (4) and (5) (Fig. 2). Full conversion to the ethyl mandelate product was obtained, but the enantioselectivity was poor (see Table 1, entries 10 and 11).

Recently we have successfully developed a family of phosphane-phosphite chiral ligands containing the TADDOL backbone, which were evaluated in this work in catalytic arylation reactions with organoboron reagents and transition metal catalysts. The ligands are schematized in Fig. $3 .^{10}$

Zhou and co-workers reported the first asymmetric Rh spirophosphite-catalysed addition of arylboronic acids to $\alpha$-ketoesters in aqueous media. ${ }^{17}$ At this point, we decided to use our TADDOL-phosphane-phosphite ligands (see Fig. 3),

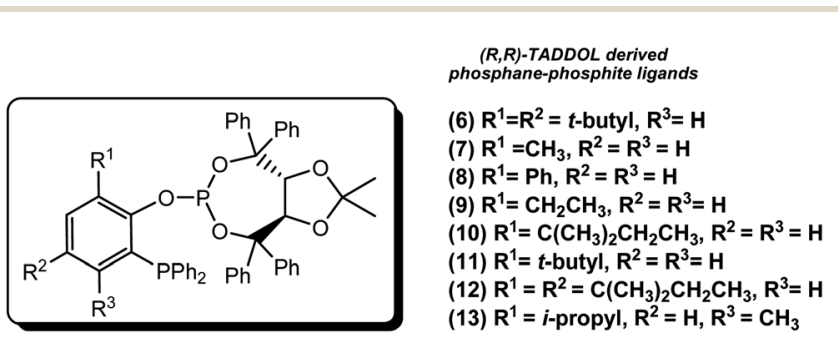

Fig. $3(R, R)$-TADDOL-derived chiral phosphane-phosphite ligands. ${ }^{10}$ 
along with $\left[\mathrm{RhCl}\left(\mathrm{C}_{2} \mathrm{H}_{4}\right)_{2}\right]_{2}$ and $\mathrm{Rh}(\mathrm{acac})\left(\mathrm{C}_{2} \mathrm{H}_{4}\right)_{2}$ pre-catalysts and $\mathrm{NaF}$ as additive, in toluene and water. The application of inorganic fluorinated bases seemed to improve significantly the yield. ${ }^{\mathbf{1 f , 1 7}}$ The results are shown in Table 2 . Generally, moderate to excellent yields were obtained with $\left[\mathrm{RhCl}\left(\mathrm{C}_{2} \mathrm{H}_{4}\right)_{2}\right]_{2}$ (see Table 2, entries 3, 4, 8, 10 and 12). This Rh pre-catalyst type has already been used successfully in several catalytic reactions. ${ }^{18}$ Despite its successful application in several other catalytic reactions, ${ }^{15}$ the use of $\mathrm{Rh}(\mathrm{acac})\left(\mathrm{C}_{2} \mathrm{H}_{4}\right)_{2}$ leads to a significant decrease in the reaction yield (see Table 2, entries 2, 11, 13 and 15). Apparently, the substitution pattern on the aromatic moiety of the TADDOL-derived phosphane-phosphite ligand backbone (see Fig. 3) doesn't seem to have a pronounced influence on the efficiency of the reaction. A maximum enantioselectivity of $69 \%$ ee was obtained for the arylation of ethyl glyoxylate with $\mathrm{Rh}(\mathrm{a}$ cac) $\left(\mathrm{C}_{2} \mathrm{H}_{4}\right)_{2}$ and the TADDOL-phosphane-phosphite ligand (10) (Table 2, entry 17). It seems that there is a slight temperature effect on the reaction enantioselectivity, since on conducting the experiment at $50{ }^{\circ} \mathrm{C}$ and room temperature no significant difference was noted (Table 2, compared entries 9 and 17), but when the experiment was conducted at $0{ }^{\circ} \mathrm{C}$ there was a significant difference in the enantioselectivity and in the yield (Table 2, compare entries 9 and 17 with entry 18). In general, the use $\left[\mathrm{RhCl}\left(\mathrm{C}_{2} \mathrm{H}_{4}\right)_{2}\right]_{2}$ afforded the highest enantioselectivities

Table 2 Rh(I)-phosphane-phosphite enantioselective catalytic arylation of ethyl glyoxylate with phenylboronic acid

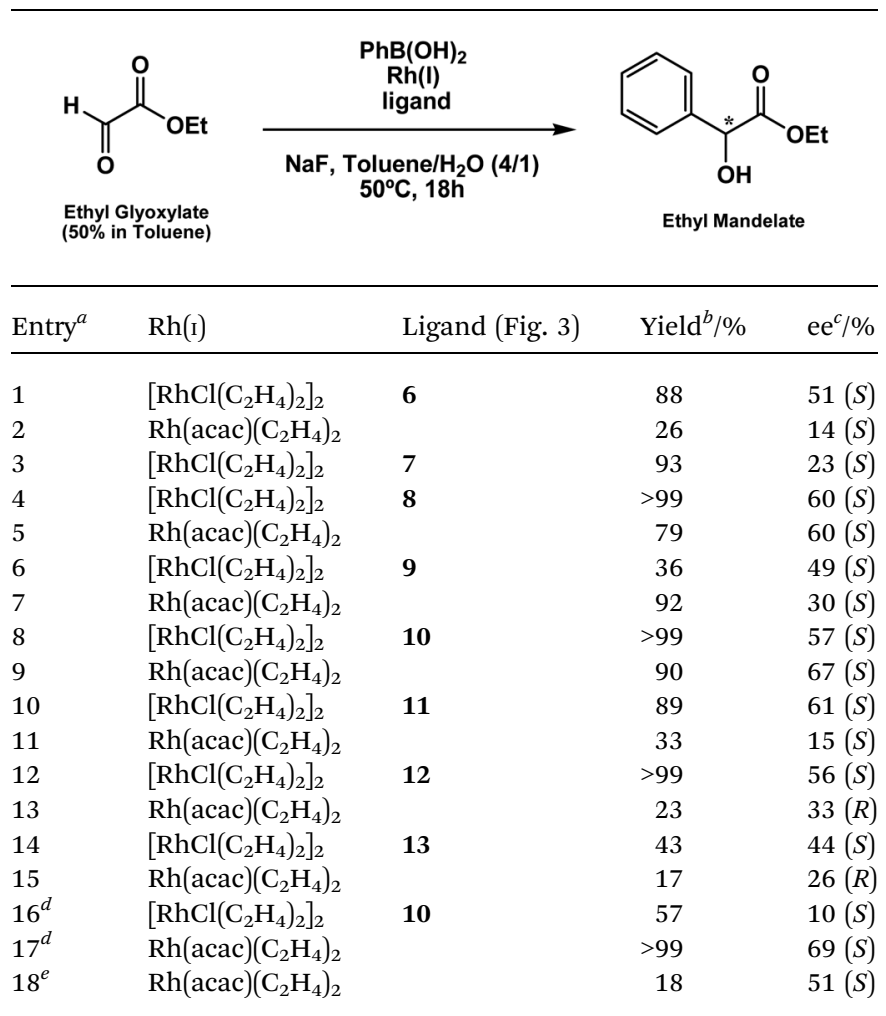

${ }^{a}$ Reaction conditions: $1.5 \quad \mathrm{~mol} \% \quad\left[\mathrm{RhCl}\left(\mathrm{C}_{2} \mathrm{H}_{4}\right)_{2}\right]_{2} \quad$ or $3 \quad \mathrm{~mol} \%$ $\mathrm{Rh}(\mathrm{acac})\left(\mathrm{C}_{2} \mathrm{H}_{4}\right)_{2}, \quad 6$ mol\% Ligand, 2 equivalents $\mathrm{PhB}(\mathrm{OH})_{2}, \quad 2$ equivalents NaF, $2 \mathrm{ml}$ solvent, $100 \mu \mathrm{l}$ ethyl glyoxylate. ${ }^{b}$ Isolated yield after silica gel chromatography. ${ }^{c}$ Determined by chiral stationary phase HPLC. ${ }^{d}$ Reaction run at room temperature. ${ }^{e}$ Reaction run at $0{ }^{\circ} \mathrm{C}$.
(Table 2, entries 1, 4, 6, 10, 12 and 14, ranging from 44-61\% ee). The lowest enantioselectivity value obtained with the use of this Rh-pre-catalyst and the less bulky TADDOL-phosphane-phosphite ligand (7) was $23 \%$ ee (Table 2 , entry 3 ). So, it seems that the size of the substituents on the phenyl ring in the ligand backbone has an effect on the reaction enantioselectivity.

No big difference between aliphatic and aromatic substituents was observed, for example compare ligand (8) with (10) (Table 2, entries 4 and 8), where the enantioselectivities obtained were practically the same. The $(S)$-enantiomer of the ethyl mandelate product was the major isomer obtained in most of the reactions.

After these preliminary test studies, we decided to select $\left[\mathrm{RhCl}\left(\mathrm{C}_{2} \mathrm{H}_{4}\right)_{2}\right]_{2}$ as the pre-catalyst and the TADDOL-phosphanephosphite ligands (8) and (12) (see Fig. 3) for further studies. The use of different phenyl-organoboron sources and bases was evaluated. The results can be seen in Table 3 .

The highest obtained enantioselectivity was $56 \%$ ee with $\mathrm{C}_{9} \mathrm{H}_{11} \mathrm{BO}_{2}$. It was observed that the yields for the ethyl mandelate product decreased significantly (Table 3 ). In fact, the more anhydrous arylboron reagents, like potassium trifluoro(phenyl)borate $\left(\mathrm{PhBF}_{3} \mathrm{~K}\right)$, triphenylborane $\left(\mathrm{Ph}_{3} \mathrm{~B}\right)$, sodium tetraphenylborate $\left(\mathrm{Ph}_{4} \mathrm{BNa}\right)$ and 1,3-propanediol boronic ester $\left(\mathrm{C}_{9} \mathrm{H}_{11} \mathrm{BO}_{2}\right)$ (Table 3 , entries 1 to 4 , respectively), previously evaluated in the enantioselective arylation of activated imines with Ru catalysts, ${ }^{1 c}$ gave poorer results than phenylboronic acid, and thus phenylboronic acid was identified as the organoboron reagent of choice in this reaction (compare Table 2 with Table

Table 3 Screening of different phenyl-organoboron reagents and bases in the $\mathrm{Rh}(1)$ - phosphane-phosphite enantioselective arylation of ethyl glyoxylate

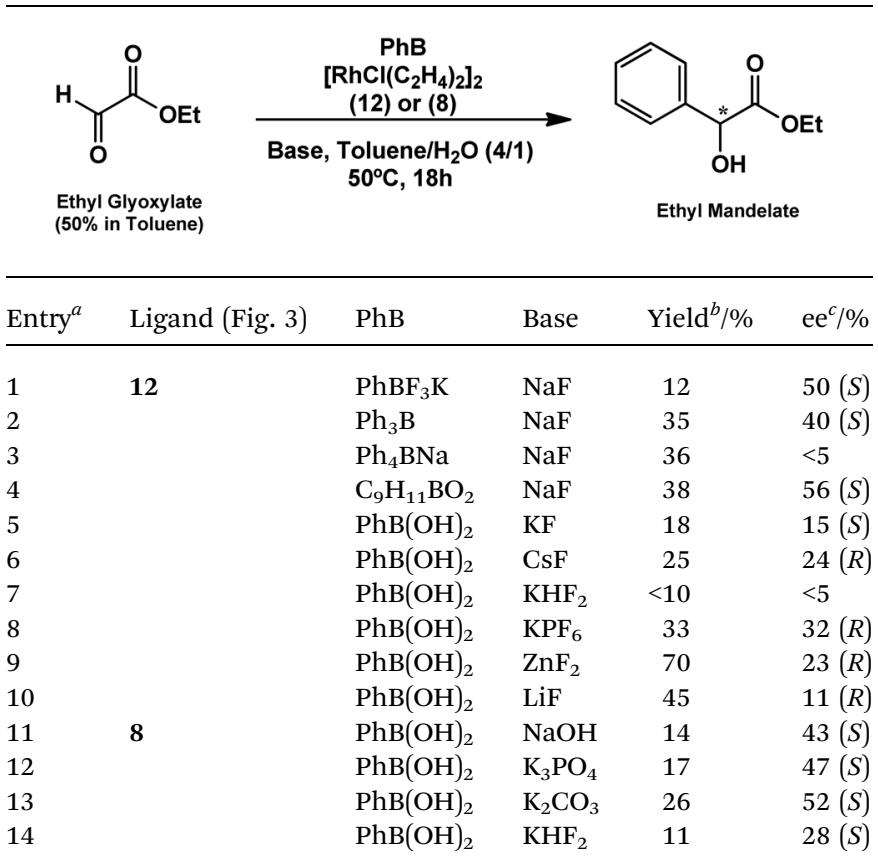

${ }^{a}$ Reaction conditions: $1.5 \mathrm{~mol} \%\left[\mathrm{RhCl}\left(\mathrm{C}_{2} \mathrm{H}_{4}\right)_{2}\right]_{2}, 6 \mathrm{~mol} \%$ Ligand, 2 equivalents phenyl-organoboron reagent, 2 equivalents base, $2 \mathrm{ml}$ solvent, $100 \mu \mathrm{l}$ ethyl glyoxylate. ${ }^{b}$ Isolated yield after silica gel chromatography. ${ }^{c}$ Determined by chiral stationary phase HPLC. 
$3)$. In the case of the base, NaF was undoubtedly the right choice (compare Table 2, entry 12 with Table 3, entries 5 to 10 and Table 2, entry 4 with Table 3, entries 11 to 14). Curiously, when other fluoride derivatives like $\mathrm{CsF}, \mathrm{ZnF}_{2}$ or LiF where used, the major enantiomer of ethyl mandelate was determined to have the $(R)$ absolute configuration, contrary to when NaF was used (see Table 2). At this juncture, we do not have a plausible explanation to account for these facts. We decided to screen other commercially available Rh(I) pre-catalysts, including screening various solvents, using our optimized procedure (see Table 2, entry 17). The results are given in Table 4 .

The results were quite disappointing, since in general both yield and enantioselectivity decreased significantly (compare Table 2, entry 17 with Table 4, entries 1 to 5). Curiously, upon using acetone as solvent, the absolute configuration of the major product enantiomer switched from $(S)$ to $(R)$ (Table 4 , entry 4 , last column). Toluene was undoubtedly the solvent of choice for this transformation. We decided to evaluate the effect of silver salts on this transformation, since we already reported their success in similar arylation reactions using organoboron reagents. ${ }^{1 c}$ In fact, a pronounced counter-ion effect was noted since there was an increase in both the yield and the enantioselectivity (Table 4, compare entries 5 and 6). To evaluate the effect of $\mathrm{AgBF}_{4}$ on the reaction, we decided to test it using all the $\mathrm{Rh}$ pre-catalysts and ligand (8) (Fig. 3). $[\mathrm{Rh}(\mathrm{nbd}) \mathrm{Cl}]_{2}$ gave the best balanced overall results.

In order to probe the reaction scope, we decided to screen several arylboronic acids bearing electron-donating and electron-withdrawing substituents in the ortho, meta and parapositions of the phenyl ring (Table 5). Two methods (A and B)

Table 4 Solvent and catalyst screening study for the Rh(I)-catalysed enantioselective arylation of ethyl glyoxylate

\begin{tabular}{|c|c|c|c|c|c|}
\hline \multicolumn{2}{|c|}{$\begin{array}{l}\text { Ethyl Glyoxylate } \\
\text { (50\% in Toluene) }\end{array}$} & \multicolumn{2}{|c|}{$\begin{array}{c}\mathrm{PhB}(\mathrm{OH})_{2} \\
\mathrm{Rh}(\mathrm{I}) /(10) \\
\begin{array}{c}\text { Solvent/ } \mathrm{H}_{2} \mathrm{O}(4 / 1) \\
\text { rt, } 18 \mathrm{~h}\end{array}\end{array}$} & \multicolumn{2}{|c|}{$\begin{array}{c}\text { OH } \\
\text { Ethyl Mandelate }\end{array}$} \\
\hline Entry $^{a}$ & $\operatorname{Rh}(\mathrm{I})$ & & Solvent & Yield $^{b} / \%$ & $\mathrm{ee}^{c} / \%$ \\
\hline 1 & Rh(aca & $\left(\mathrm{C}_{2} \mathrm{H}_{4}\right)_{2}$ & THF & 27 & $54(S)$ \\
\hline 2 & Rh(aca & $\left(\mathrm{C}_{2} \mathrm{H}_{4}\right)_{2}$ & 1,4-Dioxane & 25 & $37(S)$ \\
\hline 3 & Rh(aca & $\left(\mathrm{C}_{2} \mathrm{H}_{4}\right)_{2}$ & DME & 0 & - \\
\hline 4 & Rh(aca & $\left(\mathrm{C}_{2} \mathrm{H}_{4}\right)_{2}$ & Acetone & 14 & $35(R)$ \\
\hline 5 & {$[\mathrm{RhCl}(\mathrm{C}$} & DD) $]_{2}$ & Toluene & 46 & $<5$ \\
\hline $6^{e}$ & {$[\mathrm{RhCl}(\mathrm{C}$} & (DD) $]_{2}$ & Toluene & 70 & $37(R)$ \\
\hline $7^{d, e, f}$ & Rh(aca & $\left(\mathrm{C}_{2} \mathrm{H}_{4}\right)_{2}$ & Toluene & 9 & $41(S)$ \\
\hline $8^{d, e, f}$ & {$[\mathrm{RhCl}(\mathrm{C}$} & $\left.\left(\mathrm{H}_{4}\right)_{2}\right]_{2}$ & Toluene & 16 & $60(S)$ \\
\hline $9^{d, f}$ & {$[\mathrm{Rh}(\mathrm{nb}$} & $\mathrm{Cl}]_{2}$ & Toluene & 24 & $54(S)$ \\
\hline $10^{d, e, f}$ & {$[\mathrm{Rh}(\mathrm{nb}$} & $\mathrm{Cl}]_{2}$ & Toluene & 43 & $61(S)$ \\
\hline
\end{tabular}

${ }^{a}$ Reaction conditions: $1.5 \mathrm{~mol} \%[\mathrm{Rh}(\mathrm{I})]_{2}$ or $3 \mathrm{~mol} \%[\mathrm{Rh}(\mathrm{I})], 6 \mathrm{~mol} \%$ Schmalz Ligand (10), 2 equivalents $\mathrm{PhB}(\mathrm{OH})_{2}$, 2 equivalents $\mathrm{NaF}, 2 \mathrm{ml}$ solvent, $100 \mu \mathrm{l}$ ethyl glyoxylate. ${ }^{b}$ Isolated yield after silica gel chromatography. ${ }^{c}$ Determined by chiral stationary phase HPLC. ${ }^{d}$ Reaction run at $50{ }^{\circ} \mathrm{C} .{ }^{e} 3.3 \mathrm{~mol} \% \mathrm{AgBF}_{4}$ was added to the reaction vessel. ${ }^{f}$ Ligand (8) was used. were evaluated. Method A consisted in the use of $\mathrm{Rh}(\mathrm{a}$ cac) $\left(\mathrm{C}_{2} \mathrm{H}_{4}\right)_{2}$ along with (R)-MonoPhos ligand (3) (Fig. 2), KOtBu as base and $t$-amyl-alcohol as solvent (optimized conditions from Table 1). Method B consisted in the use of $\left[\operatorname{RhCl}\left(\mathrm{C}_{2} \mathrm{H}_{4}\right)_{2}\right]_{2}$ along with $(R, R)$-TADDOL-phosphane-phosphite ligands (8) and (11) (Fig. 3), with NaF as base in toluene and water (4/1) (optimized conditions from Table 2). In general, method A afforded the best results (Table 5, entries 5, 7, 11, 13, 15 and 16). With the exception of 2-naphthylboronic acid and 4-fluorophenylboronic acid, which worked better in the case of method B (Table 5, entries 4 and 10). As regards electronic effects, apparently no significant differences were found when electron-withdrawing or electron-donating substituents were present in the phenyl ring of the organoboron reagent (see Table 5, compare for instance entry 8 with entry 12 , and entry 1 with entry 3 ). On the other hand, the reaction seems to suffer from steric hindrance. For instance, in the case of 1 or 2-naphthylboronic acid method A worked best for the former and method $\mathrm{B}$ for the latter (Table 5, compare entries 4 and 12 (method B)). The reaction enantioselectivity was generally poor,

Table 5 Reaction scope for the Rh(I)-catalytic arylation of ethyl glyoxylate with various arylboronic acids ${ }^{a}$

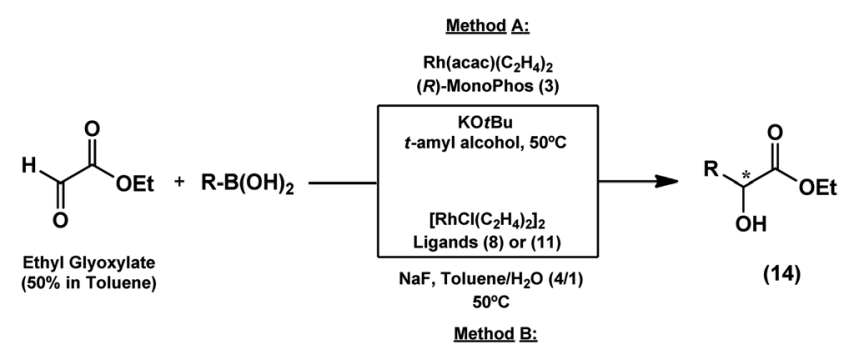

\begin{tabular}{|c|c|c|c|c|c|}
\hline Entry $^{a}$ & $\mathrm{R}$ & (14) & Method & Yield $^{b} / \%$ & $\mathrm{ee}^{c} / \%$ \\
\hline 1 & $3-\mathrm{AcC}_{6} \mathrm{H}_{4}$ & $\mathbf{a}$ & A & 16 & $<10$ \\
\hline $2^{d}$ & & & B & $<10$ & 13 \\
\hline 3 & 2-Naphthyl & b & $\mathrm{A}$ & 16 & $<5$ \\
\hline $4^{d}$ & & & B & 82 & 35 \\
\hline 5 & $4-\mathrm{ClC}_{6} \mathrm{H}_{4}$ & c & A & 23 & $32(S)$ \\
\hline $6^{d}$ & & & B & 13 & $12(S)$ \\
\hline 7 & $3-\mathrm{MeOC}_{6} \mathrm{H}_{4}$ & d & A & 32 & $<5$ \\
\hline $8^{d}$ & & & B & 11 & 29 \\
\hline 9 & $4-\mathrm{FC}_{6} \mathrm{H}_{4}$ & e & A & 18 & $<5$ \\
\hline $10^{e}$ & & & B & 50 & $28(R)$ \\
\hline 11 & 1-Naphthyl & f & A & 76 & 14 \\
\hline $12^{e}$ & & & B & 12 & 55 \\
\hline 13 & 2-Furyl & $\mathrm{g}$ & A & 71 & $<10$ \\
\hline $14^{e}$ & & & B & 39 & $<10$ \\
\hline 15 & $2-\mathrm{MeOC}_{6} \mathrm{H}_{4}$ & h & A & 30 & n.d. \\
\hline 16 & $4-\mathrm{MeOC}_{6} \mathrm{H}_{4}$ & i & A & 18 & 15 \\
\hline 17 & 3- $\mathrm{NH}_{2} \mathrm{C}_{6} \mathrm{H}_{4}$ & $\mathbf{j}$ & A & Traces & n.d. \\
\hline
\end{tabular}

${ }^{a}$ Reaction conditions: Method A: $3 \mathrm{~mol} \% \mathrm{Rh}(\mathrm{acac})\left(\mathrm{C}_{2} \mathrm{H}_{4}\right)_{2}, 3.3 \mathrm{~mol} \%(R)$ MonoPhos (3), 2 equivalents $\mathrm{R}-\mathrm{B}(\mathrm{OH})_{2}, 2$ equivalents $\mathrm{KO} t \mathrm{Bu}, 1 \mathrm{ml} t$ amyl alcohol, $100 \mu \mathrm{l}$ ethyl glyoxylate. Method B: $1.5 \mathrm{~mol} \%$ $\left[\mathrm{RhCl}\left(\mathrm{C}_{2} \mathrm{H}_{4}\right)_{2}\right]_{2}, 6$ mol\% Ligand (8) or $(\mathbf{1 1}), 2$ equivalents $\mathrm{R}-\mathrm{B}(\mathrm{OH})_{2}, 2$ equivalents NaF, $2 \mathrm{ml}$ solvent, $100 \mu \mathrm{l}$ ethyl glyoxylate. ${ }^{b}$ Isolated yield after silica gel chromatography. ${ }^{c}$ Determined by chiral stationary phase HPLC. ${ }^{d}$ Ligand (8) was used. ${ }^{e}$ Ligand (11) was used. n.d. $=$ not determined. 
(Table 5, last column), but the highest enantioselectivity (55\% ee) was obtained with the 1-naphthylboronic acid reagent (Table 5, entry 12).

\section{Conclusions}

We have developed an efficient $\mathrm{Rh}(\mathrm{I})$-catalysed glyoxylate arylation reaction allowing the synthesis of mandelate derivatives in excellent yields and good enantioselectivities (up to $75 \%$ ee for a virtually unexplored reaction). This procedure was applied for the first time with chiral phosphorous-containing Rh(I) catalysts. Several ethyl mandelate derivatives were synthesized, using two different catalytic protocols. We are currently developing an intra-molecular version of this reaction in order to access families of very interesting pharmacologically active chiral cyclo-alkanol compounds for HTS studies.

\section{Experimental}

\section{General procedures}

All the reagents were obtained from Aldrich, Fluka, Acros and Alfa Aeser. The solvents used were dried using current laboratory techniques. ${ }^{19}$ All the reagents applied in this work were used as received. All reactions were conducted under a nitrogen atmosphere. Column chromatography was carried out on silica gel (sds, 70-200 $\mu \mathrm{m}$ ). Thin layer chromatography (TLC) was carried out on aluminium backed Kiselgel 60 F254 plates (Merck). Plates were visualized either by UV light or with phosphomolybdic acid in ethanol. The NMR analyses were recorded on a Bruker Avance instrument ( $400 \mathrm{MHz}$ ) using $\mathrm{CDCl}_{3}$ as solvent and the signal from the residual $\mathrm{CHCl}_{3}$ as an internal standard. Mass spectra were recorded on a Waters-Micromass instrument (MaldiTOF, MicroTOF, ESI). High performance liquid chromatographic (HPLC) analyses were performed with an Agilent 1100 series instrument. The conditions used were, flux $=1 \mathrm{ml} \mathrm{min}{ }^{-1}$, detector $=$ wavelength light $(\lambda=210 \mathrm{~nm})$, eluent $=$ hexane $/ 2$-propanol $(90 / 10)$, and column $=$ Chiralcel OD-H $(0.46 \mathrm{~cm} \times 25 \mathrm{~cm})$ fitted with a guard column composed of the same stationary phase. Racemic mixtures were prepared using the followed procedure: $[\mathrm{RhCl}(\mathrm{COD})]_{2}\left(1.5 \mathrm{~mol} \%, 7.34 \times 10^{-3} \mathrm{mmol}\right)$ was added to a round bottom flask, under an inert atmosphere. $\mathrm{PPh}_{3}(3.3 \mathrm{~mol} \%$, $0.015 \mathrm{mmol}$ ), arylboronic acid (2 equiv., $0.98 \mathrm{mmol}$ ), KOtBu ( 1 equiv., $0.49 \mathrm{mmol}$ ) and $t$-amyl alcohol $(1 \mathrm{ml})$ were added sequentially. Finally, ethyl glyoxylate ( $50 \%$ in toluene, $0.49 \mathrm{mmol}$, $100 \mu \mathrm{l})$ was added and the reaction was stirred at $60{ }^{\circ} \mathrm{C}$, and monitored by TLC. The crude mixture was passed through a porous ceramic glass filter and eluted with $\mathrm{CH}_{2} \mathrm{Cl}_{2}$. The solvents were concentrated under reduced pressure and the residue purified by liquid chromatography $\left(\mathrm{SiO}_{2}\right.$ gel, hexane/AcOEt (5/1)), yielding the desired racemic ethyl mandelate derivative product.

\section{Catalytic reactions}

Method A. $[\mathrm{Rh}(\mathrm{I})]_{2}\left(1.5 \mathrm{~mol} \%, 7.34 \times 10^{-3} \mathrm{mmol}\right)$ or $[\mathrm{Rh}(\mathrm{I})]$ (3 mol\%, $0.015 \mathrm{mmol}$ ) was added to a round bottom flask, under an inert atmosphere. Commercial phosphane ligand (3.3 mol\%, $0.015 \mathrm{mmol}$ ), arylboronic acid or derivative (2 equiv.,
$0.98 \mathrm{mmol}$ ), KOtBu (1 equiv., $0.49 \mathrm{mmol}$ ), and $t$-amyl alcohol $(1 \mathrm{ml})$ were added sequentially. Finally, ethyl glyoxylate (50\% in toluene, $0.49 \mathrm{mmol}, 100 \mu \mathrm{l}$ ) was added and the reaction was stirred at the desired temperature, and monitored by TLC. The crude mixture was passed through a porous ceramic glass filter and eluted with $\mathrm{CH}_{2} \mathrm{Cl}_{2}$. The solvents were concentrated under reduced pressure and the residue purified by liquid chromatography $\left(\mathrm{SiO}_{2}\right.$ gel, hexane/AcOEt (5/1)), yielding the desired ethyl mandelate derivative product.

Method B. $\left[\mathrm{RhCl}\left(\mathrm{C}_{2} \mathrm{H}_{4}\right)_{2}\right]_{2}\left(1.5 \mathrm{~mol} \%, 7.34 \times 10^{-3} \mathrm{mmol}\right)$ or $\mathrm{Rh}$ (acac) $\left(\mathrm{C}_{2} \mathrm{H}_{4}\right)_{2}(3 \mathrm{~mol} \%, 0.015 \mathrm{mmol})$ was added to a round bottom flask, under a nitrogen atmosphere. The chiral TADDOL-phosphane-phosphite ligands ( $6 \mathrm{~mol} \%, 0.030 \mathrm{mmol})$ and toluene $(1.6 \mathrm{ml})$ were added to the reaction vessel. The mixture was stirred at $50{ }^{\circ} \mathrm{C}$ during 30 minutes, which was followed by the sequential addition of the arylboronic acid or derivative ( 2 equiv., $0.98 \mathrm{mmol}$ ), $\mathrm{NaF}$ ( 2 equiv., $0.98 \mathrm{mmol})$, and water $(0.4$ $\mathrm{ml}$ ). Finally, ethyl glyoxylate ( $50 \%$ in toluene, $0.49 \mathrm{mmol}, 100 \mu \mathrm{l})$ was added and the reaction was stirred at the desired temperature, and monitored by TLC. The reaction was quenched with water $(10 \mathrm{ml})$ and extracted with AcOEt $(3 \times 10 \mathrm{ml})$. The combined organic layers were dried with anhydrous $\mathrm{MgSO}_{4}$, filtered and concentrated under reduced pressure. The crude residue was purified by liquid chromatography $\left(\mathrm{SiO}_{2}\right.$ gel, hexane/AcOEt (5/1)), yielding the desired ethyl mandelate derivative product.

Ethyl mandelate:. ${ }^{1 d, e}$ Colorless oil. ${ }^{1} \mathrm{H} \mathrm{NMR}\left(\mathrm{CDCl}_{3}, 400 \mathrm{MHz}\right)$ $\delta$ ppm: 1.21 (m, 3H, $\left.\mathrm{CH}_{3}\right), 3.56$ (br s, $\left.1 \mathrm{H}, \mathrm{OH}\right), 4.17-4.26(\mathrm{~m}, 2 \mathrm{H}$, $\left.\mathrm{CH}_{2}\right), 5.16(\mathrm{~s}, 1 \mathrm{H}, \mathrm{CH}), 7.34-7.42(\mathrm{~m}, 5 \mathrm{H}, \mathrm{Ar}) .{ }^{13} \mathrm{C} \mathrm{NMR}\left(\mathrm{CDCl}_{3}\right.$, $100 \mathrm{MHz}) \delta$ ppm: 14.14, 62.33, 73.01, 126.63, 128.49, 128.66, 138.53, 173.76. HPLC: $t_{\mathrm{R}}: 7.4 \mathrm{~min}(S)$ and $12.1 \mathrm{~min}(R)$.

Ethyl 2-(3-acetylphenyl)-2-hydroxyacetate (12a):: ${ }^{1 d, e}$ Colorless oil. ${ }^{1} \mathrm{H} \mathrm{NMR}\left(\mathrm{CDCl}_{3}, 400 \mathrm{MHz}\right) \delta: 1.25\left(\mathrm{~m}, 3 \mathrm{H}, \mathrm{CH}_{3}\right), 2.62(\mathrm{~s}, 3 \mathrm{H}$, $\mathrm{CH}_{3}$ (Ac)), 4.19-4.41 (m, 2H, $\left.\mathrm{CH}_{2}\right), 5.35$ (s, 1H, CH), 7.32-7.66 (m, 2H, Ar), 7.69-8.04 (m, 2H, Ar). ${ }^{13} \mathrm{C} \mathrm{NMR}\left(\mathrm{CDCl}_{3}, 100 \mathrm{~Hz}\right) \delta$ : $14.03,22.62,62.83,72.39$, 128.41, 128.66, 129.01, 131.30, 137.55, 139.17, 173.06, 198.14. ESI-TOF MS $(\mathrm{m} / \mathrm{z}) 223.10(\mathbf{M}+1)$. HPLC: $t_{\mathrm{R}}: 18.5 \mathrm{~min}$ and $20.9 \mathrm{~min}$.

Ethyl 2-hydroxy-2-(naphthalen-2-yl)acetate (12b):. ${ }^{1 d, e}$ White solid. ${ }^{1} \mathrm{H} \mathrm{NMR}\left(\mathrm{CDCl}_{3}, 400 \mathrm{MHz}\right) \delta: 1.20\left(\mathrm{~m}, 3 \mathrm{H}, \mathrm{CH}_{3}\right), 3.71$ (br s, $1 \mathrm{H}, \mathrm{OH}), 4.13-4.19\left(\mathrm{~m}, 1 \mathrm{H}, \mathrm{CH}_{2}\right), 4.21-4.30\left(\mathrm{~m}, 1 \mathrm{H}, \mathrm{CH}_{2}\right), 5.33$ (s, 1H, CH), 7.47-7.54 (m, 3H, Ar), 7.83-7.85 (m, 3H, Ar), 7.91 (s, $1 \mathrm{H}, \mathrm{Ar}) .{ }^{13} \mathrm{C} \mathrm{NMR}\left(\mathrm{CDCl}_{3}, 100 \mathrm{MHz}\right) \delta: 14.45,62.40,73.08$, $124.17,125.90,126.06,126.33$, 127.91, 128.34, 128.62, 133.28, 133.38, 135.89, 173.84. ESI-TOF MS $(\mathrm{m} / \mathrm{z}): 213.10(-\mathrm{OH}), 231.10$ $(\mathrm{M}+1)$. HPLC: $t_{\mathrm{R}}: 11.0 \mathrm{~min}$ and $13.5 \mathrm{~min}$.

Ethyl 2-(4-chlorophenyl)-2-hydroxyacetate (12c):. ${ }^{1 d, e}$ Light yellow solid. ${ }^{1} \mathrm{H}$ NMR $\left(\mathrm{CDCl}_{3}, 400 \mathrm{MHz}\right) \delta: 1.06\left(\mathrm{~m}, 3 \mathrm{H}, \mathrm{CH}_{3}\right)$, 4.00-4.05 (m, 2H, $\mathrm{CH}_{2}$ ), 4.99 (s, 1H, CH), 7.15-7.25 (m, 2H, Ar), 7.63-7.65 (m, 2H, Ar). ${ }^{13} \mathrm{C} \mathrm{NMR}\left(\mathrm{CDCl}_{3}, 100 \mathrm{MHz}\right) \delta: 14.12$, 64.06, 71.82, 128.02, 128.36, 129.18, 129.55, 137.11, 137.14, 169.66. ESI-TOF MS $(\mathrm{m} / \mathrm{z}): 213.11$. HPLC: $t_{\mathrm{R}}: 7.1 \mathrm{~min}(S)$ and 8.1 $\min (R)$.

Ethyl 2-hydroxy-2-(3-methoxyphenyl)acetate (12d):. ${ }^{1 d, e}$ Yellow oil. ${ }^{1} \mathrm{H}$ NMR $\left(\mathrm{CDCl}_{3}, 400 \mathrm{MHz}\right) \delta: 1.21\left(\mathrm{~m}, 3 \mathrm{H}, \mathrm{CH}_{3}\right), 3.63$ (br s, $1 \mathrm{H}, \mathrm{OH}), 3.78\left(\mathrm{~s}, 3 \mathrm{H}, \mathrm{OCH}_{3}\right), 4.14-4.19\left(\mathrm{~m}, 1 \mathrm{H}, \mathrm{CH}_{2}\right), 4.20-4.28$ (m, 1H, $\mathrm{CH}_{2}$ ), 5.12 (s, 1H, CH), 6.83-6.85 (m, 1H, Ar), 6.96-6.98 
(m, 2H, Ar), 7.23-7.27 (m, 1H, Ar). ${ }^{13} \mathrm{C} \mathrm{NMR}\left(\mathrm{CDCl}_{3}, 100 \mathrm{MHz}\right) \delta$ : $13.96,55.29,62.14,72.61,111.85,114.32,118.92,129.46$, 140.23, 159.73, 173.97. ESI-TOF MS ( $\mathrm{m} / \mathrm{z}): 193.09$ (-OH), 211.10 $(\mathrm{M}+1)$. HPLC: $t_{\mathrm{R}}: 14.3 \mathrm{~min}$ and $17.6 \mathrm{~min}$.

Ethyl 2-(4-fluorophenyl)-2-hydroxyacetate (12e):: ${ }^{1 d, e}$ Colorless oil. ${ }^{1} \mathrm{H} \mathrm{NMR}\left(\mathrm{CDCl}_{3}, 400 \mathrm{MHz}\right) \delta: 1.16\left(\mathrm{~m}, 3 \mathrm{H}, \mathrm{CH}_{3}\right), 3.88$ (br s, $1 \mathrm{H}, \mathrm{OH}), 4.12-4.18\left(\mathrm{~m}, 1 \mathrm{H}, \mathrm{CH}_{2}\right), 4.20-4.24\left(\mathrm{~m}, 1 \mathrm{H}, \mathrm{CH}_{2}\right), 5.11$ (s, 1H, CH), 6.99-7.03 (m, 2H, Ar), 7.36-7.40 (m, 2H, Ar). ${ }^{13} \mathrm{C}$ NMR $\left(\mathrm{CDCl}_{3}, 100 \mathrm{MHz}\right) \delta: 14.15,62.36,71.47,115.49,115.61$, 128.24, 134.37, 161.42, 164.06, 173.67. ESI-TOF MS ( $\mathrm{m} / \mathrm{z}): 181.07$ $(-\mathrm{OH}), 199.08(\mathrm{M}+1)$. HPLC: $t_{\mathrm{R}}: 6.9 \mathrm{~min}(S)$ and $8.2 \mathrm{~min}(R)$.

Ethyl 2-hydroxy-2-(naphthalen-1-yl)acetate (12f):. ${ }^{1, e}$ White solid. ${ }^{1} \mathrm{H} \mathrm{NMR}\left(\mathrm{CDCl}_{3}, 400 \mathrm{MHz}\right) \delta: 1.26\left(\mathrm{~m}, 3 \mathrm{H}, \mathrm{CH}_{3}\right), 4.12-4.32$ (m, 2H, $\mathrm{CH}_{2}$ ), 5.81 (s, 1H, CH), 7.44-7.70 (m, 4H, Ar), 7.84-7.96 (m, 2H, Ar), 8.11-8.18 (m, 1H, Ar). ${ }^{13} \mathrm{C} \mathrm{NMR}\left(\mathrm{CDCl}_{3}, 100 \mathrm{MHz}\right) \delta$ : 14.17 , 62.06, 71.33, 123.46, 123.70, 125.13, 125.68, 125.78, $126.48,127.84,128.80,129.36,134.07,174.48$. ESI-TOF MS $(\mathrm{m} / \mathrm{z}): 233.08(\mathrm{M}+2)$. HPLC: $t_{\mathrm{R}}: 55.8 \mathrm{~min}$ and $36.2 \mathrm{~min}$. (HPLC eluent: hexane/2-propanol (98/2)).

Ethyl 2-(furan-2-yl)-2-hydroxyacetate (12g):: ${ }^{1 d, e}$ Yellow oil. ${ }^{1} \mathrm{H}$ NMR $\left(\mathrm{CDCl}_{3}, 400 \mathrm{MHz}\right) \delta: 1.20\left(\mathrm{~m}, 3 \mathrm{H}, \mathrm{CH}_{3}\right), 4.27-4.30(\mathrm{~m}, 2 \mathrm{H}$, $\mathrm{CH}_{2}$ ), 5.18 (s, 1H, CH), 6.37 (m, 2H, CH-CH), 7.40 (m, 1H, OCH). ${ }^{13} \mathrm{C} \mathrm{NMR}\left(\mathrm{CDCl}_{3}, 100 \mathrm{MHz}\right) \delta: 14.10,62.60,67.03,108.45$, 110.55, 143.09, 151.05, 171.47. ESI-TOF MS $(\mathrm{m} / \mathrm{z}): 153.05(-\mathrm{OH})$, $171.06(\mathrm{M}+1)$. HPLC: $t_{\mathrm{R}}: 8.9 \mathrm{~min}$ and $10.8 \mathrm{~min}$.

Ethyl 2-hydroxy-2-(2-methoxyphenyl)acetate (12h):. ${ }^{1 d}$ Colorless oil. ${ }^{1} \mathrm{H} \mathrm{NMR}\left(\mathrm{CDCl}_{3}, 400 \mathrm{MHz}\right) \delta: 1.20\left(\mathrm{~m}, 3 \mathrm{H}, \mathrm{CH}_{3}\right), 3.91(\mathrm{~s}$, $\left.3 \mathrm{H}, \mathrm{OCH}_{3}\right), 4.17-4.26\left(\mathrm{~m}, 2 \mathrm{H}, \mathrm{CH}_{2}\right), 5.28$ (s, 1H, CH), 6.89-6.96 (m, 2H, Ar), 7.01-7.05 (m, 1H, Ar), 7.42-7.47 (m, 1H, Ar). ${ }^{13} \mathrm{C}$ $\mathrm{NMR}\left(\mathrm{CDCl}_{3}, 100 \mathrm{MHz}\right) \delta: 14.31,55.64,61.52,71.45,110.01$, $121.46,129.51,132.60,137.17,164.75,174.01$. ESI-TOF MS $(\mathrm{m} / \mathrm{z})$ : $193.10(-\mathrm{OH}), 211.10(\mathrm{M}+1)$. HPLC: not determined.

Ethyl 2-hydroxy-2-(4-methoxyphenyl)acetate (12i):. ${ }^{12}$ Colorless oil. ${ }^{1} \mathrm{H} \mathrm{NMR}\left(\mathrm{CDCl}_{3}, 400 \mathrm{MHz}\right) \delta: 1.25\left(\mathrm{~m}, 3 \mathrm{H}, \mathrm{CH}_{3}\right), 3.39(\mathrm{br}$ $\mathrm{s}, 1 \mathrm{H}, \mathrm{OH}), 3.81\left(\mathrm{~s}, 3 \mathrm{H}, \mathrm{OCH}_{3}\right), 4.15-4.28\left(\mathrm{~m}, 2 \mathrm{H}, \mathrm{CH}_{2}\right), 5.10(\mathrm{~s}$, 1H, CH), 6.88-6.90 (m, 2H, Ar), 7.32-7.34 (m, 2H, Ar). ${ }^{13} \mathrm{C}$ NMR $\left(\mathrm{CDCl}_{3}, 100 \mathrm{MHz}\right) \delta: 14.10,55.53,62.36,72.39,114.13,127.70$, 130.36, 159.95, 173.82. ESI-TOF MS ( $\mathrm{m} / \mathrm{z}): 193.08(-\mathrm{OH}), 233.08$ $\left(\mathrm{M}+1\right.$ plus Na). HPLC: $t_{\mathrm{R}}: 10.2 \mathrm{~min}$ and $14.4 \mathrm{~min}$.

Ethyl 2-(3-aminophenyl)-2-hydroxyacetate (12j):. ${ }^{1 d}$ Obtained in vestigial quantities. Colorless oil.

\section{Acknowledgements}

We are grateful for the award of a PhD grant to C.S.M. (SFRH/ $\mathrm{BD} / 45132 / 2008$ ) from the Fundação para a Ciência e a Tecnologia (FCT) 2010. We are grateful for funding from strategic project PEst-OE/QUI/UI0619/2011 (CQE-UE). We acknowledge LabRMN at FCT-UNL for the acquisition of the NMR spectra; the NMR spectrometers are part of the National NMR Network and were purchased within the framework of the National Programme for Scientific Re-equipment (contract REDE/1517/ RMN/2005), with funds from POCI 2010 (FEDER) and FCT. The C.A.C.T.I. at the University of Vigo (Spain) is gratefully acknowledged for MS analysis.

\section{Notes and references}

1 (a) C. S. Marques and A. J. Burke, Eur. J. Org. Chem., 2010, 1639-1643; (b) C. S. Marques and A. J. Burke, ChemCatChem, 2011, 3, 635-645; (c) C. S. Marques and A. J. Burke, Eur. J. Org. Chem., 2012, 4232-4239; (d) C. S. Marques and A. J. Burke, Tetrahedron, 2012, 68, 72117216; (e) C. S. Marques and A. J. Burke, Tetrahedron: Asymmetry, 2013, 24, 628-632; $(f)$ C. S. Marques and A. J. Burke, Tetrahedron, 2013, 69, 10091-10097.

2 G. M. Copola and H. F. Schuster, $\alpha$-Hydroxy Acids in Enantioselective Synthesis, Wiley-VCH, Weinheim, 1997.

3 (a) Privileged Chiral Ligands and Catalysts, ed. Q.-L. Zhou, Wiley-VCH, 2011; (b) Phosphorus Ligands in Asymmetric Catalysis, ed. A. Börner, Wiley-VCH, 2008, vol. 1-3.

4 For some selected examples see: (a) S. Morikawa, K. Michigami and H. Amii, Org. Lett., 2010, 12, 2520-2523; (b) M. Ueda and N. Miyaura, J. Org. Chem., 2000, 65, 44504452; (c) D. Tomita, M. Kanai and M. Shibasaki, Chem.Asian J., 2006, 1-2, 161-166; (d) F. Sakurai, K. Kondo and T. Aoyama, Tetrahedron Lett., 2009, 50, 6001-6003; (e) Y. Yamamoto, K. Kurihara and N. Miyaura, Angew. Chem., Int. Ed., 2009, 48, 4414-4416.

5 M. Diéguez, O. Pámies and C. Claver, Tetrahedron: Asymmetry, 2004, 15, 2113-2122.

6 A. Alexakis, J. E. Bäckvall, N. Krause, O. Pámies and M. Diéguez, Chem. Rev., 2008, 108, 2796-2823.

7 For recent reviews see: (a) P. W. N. M. van Leeuwen, P. C. J. Kamer, C. Claven, O. Pámies and M. Diéguez, Chem. Rev., 2011, 111, 2077-2118; (b) H. Fernández-Pérez, P. Etayo, A. Panossian and A. Vidal-Ferran, Chem. Rev., 2011, 111, 2119-2176; (c) S. Lühr, J. Holtz and A. Börner, ChemCatChem, 2011, 3, 1708-1730.

8 D. Seebach, A. K. Beck and A. Heckel, Angew. Chem., Int. Ed., 2001, 40, 92-138.

9 (a) U. Berens, D. Leckel and S. C. Oepen, J. Org. Chem., 1995, 60, 8204-8208; (b) D. Haag, J. Runsink and H.-D. Scharf, Organometallics, 1998, 17, 398-409.

10 (a) T. Robert, J. Velder and H.-G. Schmalz, Angew. Chem., Int. Ed., 2008, 47, 7718-7721; (b) Q. Naeemi, T. Robert, D. P. Kranz, J. Velder and H.-G. Schmalz, Tetrahedron: Asymmetry, 2011, 22, 887-892; (c) W. Lölsberg, S. Ye and H.-G. Schmalz, Adv. Synth. Catal., 2010, 2023-2031; (d) W. Lölsberg, S. Werle, J.-M. Neudörfl and H.-G. Schmalz, Org. Lett., 2012, 14, 5996-5999; (e) T. Robert, Z. Abiri, J. Wassenaar, A. J. Sandee, S. Romanski, J.-M. Neudörfl, H.-G. Schmalz and J. N. H. Reek, Organometallics, 2010, 29, 478-483; $(f)$ A. Falk, A.-L. Göderz and H.-G. Schmalz, Angew. Chem., Int. Ed., 2013, 52, 1576-1580; (g) M. A. Bohn, A. Schmidt, G. Hilt, M. Dindaroğlu and H.-G. Schmalz, Angew. Chem., Int. Ed., 2011, 50, 9689-9693; (h) M. Arndt, M. Dindaroğlu, H.-G. Schmalz and G. Hilt, Org. Lett., 2011, 13, 6236-6239; (i) A. Falk, L. Fiebig, J.-M. Neudörfl, A. Adler and H.-G. Schmalz, Adv. Synth. Catal., 2011, 353, 3357-3362; (j) M. Dindaroğlu, S. Akyol, H. Şimşir, J.-M. Neudörfl, A. Burke and H.-G. Schmalz, Tetrahedron: 
Asymmetry, 2013, 24, 657-662; (k) M. Dindaroğlu, A. Falk and H.-G. Schmalz, Synthesis, 2013, 527-535.

11 (a) M. Sakai, M. Ueda and N. Miyaura, Angew. Chem., Int. Ed., 1998, 37, 3279-3281; (b) M. Ueda and N. Miyaura, J. Org. Chem., 2000, 65, 4450-4452; (c) T. Nishikata, Y. Yamamoto, I. D. Gridnev and N. Miyaura, Organometallics, 2005, 24, 5025-5032.

12 I. N. Francesco, A. Wagner and F. Colobert, Eur. J. Org. Chem., 2008, 5692-5695.

13 Y. Yamamoto, T. Shirai and N. Miyaura, Chem. Commun., 2012, 48, 2803-2805.

14 R. Kranich, K. Eis, O. Geis, S. Mühle, J. W. Bats and H.-G. Schmalz, Chem.-Eur. J., 2000, 6, 2874-2894.

15 For selected examples see: (a) Y. Takaya, M. Ogasawara and T. Hayashi, J. Am. Chem. Soc., 1998, 120, 5579-5580; (b) M. T. Reetz, D. Moulin and A. Gosberg, Org. Lett., 2001, 3, 4083-4085; (c) T. Hayashi and M. Ishigedani, J. Am. Chem. Soc., 2000, 122, 976-977; (d) J.-G. Boiteau,
A. J. Minnaard and B. L. Feringa, J. Org. Chem., 2003, 68, 9481-9484; (e) X. Hao, Q. Chen, M. Kuriyama, K.-i. Yamada, Y. Yamamoto and K. Tomioka, Catal. Sci. Technol., 2011, 1, 62-64.

16 J. F. Teichert and B. L. Feringa, Angew. Chem., Int. Ed., 2010, 49, 2486-2528.

17 H.-F. Duan, J.-H. Xie, X.-C. Qiao, L.-X. Wang and Q.-L. Zhou, Angew. Chem., Int. Ed., 2008, 47, 4351-4353.

18 For selected examples see: (a) T. Hayashi and K. Yamasaki, Chem. Rev., 2003, 103, 2829-2844; (b) T. Sugihara, T. Satoh, M. Miura and M. Nomura, Adv. Synth. Catal., 2004, 346, 1765-1772; (c) N. Tokunaga, Y. Otomaru, K. Okamoto, K. Ueyama, R. Shintani and T. Hayashi, J. Am. Chem. Soc., 2004, 126, 13584-13585; (d) T. Hayashi, K. Ueyama, N. Tokunaga and K. Yoshida, J. Am. Chem. Soc., 2003, 125, 11508-11509.

19 W. L. F. A. Perrin, Purification of Laboratory Chemicals, Butterworth Heinemann, Oxford, 4th edn, 1996. 